\title{
A contemplação da natureza e o sumo bem segundo Sêneca: tradução comentada do prefácio do livro I das Naturales Quaestiones $^{1}$
}

\author{
Willamy Fernandes Gonçalves \\ Mestrando em Letras Clássicas \\ Universidade de São Paulo (USP) \\ willamyfernandes@gmail.com
}

RESUMO: A despeito da ideia amplamente difundida de que os estoicos romanos teriam deixado de lado física e lógica e se dedicado em caráter praticamente exclusivo ao terceiro elemento da tríade estoica, a ética, conhecemos diversos títulos de Sêneca relacionados ao estudo da natureza, a física. Esses estudos abarcam temas ligados a diversas áreas de estudos, como biologia, geologia e cosmologia. Também permeiam toda a vida do filósofo, desde a sua juventude até sua velhice. Por fim, as Naturales Quaestiones são o tratado mais longo de Sêneca e sua obra mais longa, se excetuarmos a coletânea de cartas a Lucílio. No prefácio que ora traduzimos, Sêneca expõe sua visão acerca da importância do estudo da natureza e, longe de considerá-lo secundário, argumenta que se trata do sumo bem da vida humana, sem o qual mesmo uma vida perfeitamente ética deixa de ter valor.

Palavras-chave: Sêneca; natureza; ética; sumo bem.

\section{The contemplation of nature and ultimate good according to Seneca: a commented translation of the preface to book I of Naturales Quaestiones}

\begin{abstract}
Despite the widespread idea that the Roman Stoics would have left aside physics and logic and devoted themselves almost exclusively to the third element of the Stoic triad, ethics, we know several Seneca's titles related to the study of nature, physics. These studies cover topics related to several areas of

\footnotetext{
${ }^{1}$ O presente trabalho foi realizado com apoio da Coordenação de Aperfeiçoamento de Pessoal de Nível Superior - Brasil (CAPES) - Código de Financiamento 001. 0 autor agradece igualmente ao prof. Dr. Alexandre Pinheiro Hasegawa (USP), atencioso leitor das primeiras versões do texto traduzido, e aos dois pareceristas anônimos, cujos apontamentos foram de fundamental importância para a versão final ora publicada.
} 
A contemplação da natureza e o sumo bem segundo Sêneca: tradução comentada do prefácio do livro I das Naturales Quaestiones

study, such as biology, geology and cosmology. They also permeate the philosopher's entire life, from his youth to his old age. Finally, the Naturales Quaestiones are Seneca's longest treatise and his longest work if we exclude the collection of letters to Lucilius. In the preface here translated, Seneca sets out his view on the importance of the study of nature and, far from considering it secondary, argues that it is the ultimate good of human life, without which even a perfectly ethical life is worthless.

Keywords: Seneca; nature; ethics; ultimate good. 


\section{Introdução}

O aspecto menos conhecido da filosofia de Sêneca (c. 2 a. C - 65 d. C.) é provavelmente sua obra voltada para o estudo da natureza. Não obstante, conhecemos uma série de títulos e fragmentos do estoico romano devotados a temas que atribuiríamos hoje a áreas como antropologia, geografia, geologia, biologia e cosmologia. São obras monográficas de que conhecemos apenas os títulos e escassos fragmentos, como as monografias De motu terrarum ("Sobre os terremotos"), De lapidum natura ("Sobre a natureza das pedras"), De piscium natura ("Sobre a natureza dos peixes"), De situ Indiae ("Sobre a Índia"), De situ et sacris Aegypitiorum ("Sobre a terra e os costumes sagrados dos egípcios"), escritos "provavelmente de juventude" (CITRONI et alii, 2006, p. 724). Já em idade madura, durante seu exílio na Córsega (41-49), o filósofo encerra a carta consolatória que escreveu à sua mãe Hélvia com as seguintes palavras:

Qualem me cogites accipe: laetum et alacrem uelut optimis rebus. Sunt enim optimae, quoniam animus omnis occupationis expers operibus suis uacat et modo se leuioribus studiis oblectat, modo ad considerandam suam uniuersique naturam ueri auidus insurgit. Terras primum situmque earum quaerit, deinde condicionem circumfusi maris cursusque eius alternos et recursus; tunc quidquid inter caelum terrasque plenum formidinis interiacet perspicit et hoc tonitribus fulminibus uentorum flatibus ac nimborum niuisque et grandinis iactu tumultuosum spatium; tum peragratis humilioribus ad summa perrumpit et pulcherrimo diuinorum spectaculo fruitur, aeternitatis suae memor in omne quod fuit futurumque est uadit omnibus saeculis.
Fica sabendo como deves imaginar-me: feliz e alegre como se as circunstâncias fossem as melhores. Realmente, elas são ótimas, porque meu espírito, livre de qualquer preocupação, entrega-se aos seus estudos prediletos e, ora se deleita com estudos mais leves, ora, ávido de verdade, se eleva para contemplar sua natureza e a do universo. Examina antes a terra e sua posição, depois o regime do mar que a circunda e as alternâncias da baixa e da alta maré; em seguida, observa o que se interpõe entre o céu e a terra, cheio de terríveis fenômenos e este espaço perturbado pelos trovões, raios, sopros dos ventos e das nuvens, pela precipitação de neve e de granizo; finalmente, exploradas as zonas mais baixas, irrompe até o topo do céu e goza do magnífico espetáculo das coisas divinas: lembrado da sua eternidade, caminha para tudo o que foi e para tudo o que há de ser, ao longo de todos os séculos. (Ad Heluiam, 20, 2) ${ }^{2}$.

O trecho parece anunciar o início dos trabalhos que culminaram na sua obra maior sobre a natureza, as Naturales Quaestiones ("Investigações sobre a natureza") que, contudo, só seria levada a cabo nos anos finais de sua vida, quando o filósofo, já senex (NQ, III, praef. 1-2), procurava se distanciar das obrigações da corte para, mais uma vez, se dedicar aos estudos da natureza ( $D e$ otio, III). Tudo isso leva Díaz (2013, 1. 735-736)³ a concluir que:

Hoje, contudo, é difícil sustentar a ideia de um Sêneca leigo em questões científicas. Ao contrário, há razões para supor

\footnotetext{
2 Tradução de Cleonice Furtado de Mendonça van Raij (1992).

3 Trata-se de um livro digital. Por isso, utilizamos como referência a localização em vez de página.
} 
A contemplação da natureza e o sumo bem segundo Sêneca: tradução comentada do prefácio do livro I das Naturales Quaestiones

que as $N Q$, embora compostas nos últimos anos da vida de Sêneca, representam a culminância de uma vida de estudos e leituras, dedicada às ciências da natureza. ${ }^{4}$

Duas questões importantes emergem da leitura do prefácio aqui traduzido. A primeira delas é a discrepância entre a avaliação da posteridade a respeito do valor das Naturales Quaestiones no interior da obra do Sêneca, e a avaliação do próprio Sêneca. Por um lado, em harmonia com a concepção amplamente disseminada de que os estoicos romanos teriam se concentrado na ética em detrimento da física e da lógica, os outros dois elementos da tríade estoica, as Naturales Quaestiones recebem pouca atenção por parte de classicistas, sendo pouco estudadas, tendo tratamento reduzido ou nulo nos manuais de literatura latina ${ }^{5}$ e, por fim, sendo provavelmente uma das obras menos traduzidas de Sêneca: até onde pudemos averiguar, esta é a primeira tradução, mesmo parcial, da obra para a língua portuguesa ${ }^{6}$. Por outro lado, o próprio Sêneca argumenta longamente, aqui como no prefácio do livro $\mathrm{III}^{7}$, que esta é sua obra mais importante.

Um dos aspectos mais marcantes da argumentação de Sêneca neste prefácio é que, na contramão da noção, normalmente atribuída aos estoicos ${ }^{8}$, de que a virtude seria condição suficiente para a felicidade, aqui, de forma ainda mais explícita do que em outros trechos em que fala do estudo da natureza9 ${ }^{9}$, vemos Sêneca subordinar a ética à física. Mais do que mero ponto de partida para a definição do que é virtude e de um modelo ao qual devemos nos adaptar (naturam sequi), a contemplação da natureza erige-se também como ponto de chegada. Se, por um lado, o estudo da natureza é valorizado apenas na medida em que nos auxilia a alcançar uma vida virtuosa, por sua vez, o importante trabalho de livrar-nos dos vícios é apenas a necessária preparação para a

\footnotetext{
${ }^{4}$ Tradução nossa: "Hoy, sin embargo, resulta difícil sostener la idea de un Séneca lego en cuestiones científicas. Antes al contrario, hay razones para suponer que las NQ aun compuestas en los últimos años de la vida de Séneca, suponen la culminación de una vida de estudios y lecturas, dedicada a las ciencias de la naturaleza".

${ }^{5}$ Cardoso (2013, p. 177), por exemplo, apenas menciona sua existência e a resume em uma frase: "uma exposição do sistema físico do mundo, conforme a concepção estoica".

${ }^{6}$ Vale mencionar que alguns sinais de mudança podem ser percebidos nessas primeiras décadas do séc. XXI. Algra (2013, p. 175), por exemplo, nos alerta que "apesar do clichê que afirma que o estoicismo tardio só trata de ética, os testemunhos que chegaram até nós referentes às práticas escolares, aos hábitos de leitura e aos interesses pessoais dos estoicos dos primeiros séculos da nossa era mostram que a física sempre foi considerada uma parte importante da filosofia".

${ }^{7}$ Hine (1996, p. XXII-XXV) argumenta que aquele que nos chegou nos manuscritos como livro III seria originalmente o primeiro livro da obra.

8 Diógenes Laércio (VII, 127-128) atribui essa concepção a Zenão e Crisipo. Já no mundo romano, Cícero atribui essa noção sobretudo a Crisipo (Paradoxa Stoicorum, 2). Posteriormente, a atribui novamente aos estoicos nos livros III e IV de De Finibus, onde tenta refutá-la, e, por fim, dedica-se a ela no livro $\mathrm{V}$ das Tusculanae disputationes, dessa vez argumentando em seu favor.

${ }^{9}$ Veja-se Naturales Quaestiones, III, praef., Epistulae Morales 65, 15ss. e os já citados De Otio, III e Ad Heluiam, 20, 2.
} 
adequada contemplação da natureza e, através desta, para a comunhão com a divindade, que seria, esta sim, o summum bonum da vida humana.

\section{Texto latino ${ }^{10}$}

1. Quantum inter philosophiam interest, Lucili uirorum optime, et ceteras artes, tantum interesse existimo in ipsa philosophia inter illam partem quae ad homines et hanc quae ad deos pertinet. altior est haec et animosior; multum permisit sibi; non fuit oculis contenta: maius esse quiddam suspicata est ac pulchrius quod extra conspecto natura possuisset.

2. denique tantum inter duas interest quantum inter deum et hominem: altera docet quid in terris agendum sit, altera quid agatur in caelo; altera errores nostros discutit et lumen admouet quo discernantur ambigua uitae, altera multum supra hanc in qua uolutamur calignem excedit, et e tenebris ereptos perducit illo unde lucet.

3. Equidem tunc rerum naturae gratias ago cum illam non ab hac parte uideo qua publica est, sed cum secretiora eius intraui, cum disco quae uniuersi materia sit, quis auctor aut custos, quid sit deus, totus in se tendat an et ad nos aliquando respiciat, faciat cotidie aliquid an semel fecerit, pars mundi sit an mundus, liceat illi hodieque decernere et ex lege fatorum aliquid derogare, an maiestatis deminutio sit et confessio erroris mutanda fecisse. <sed > necesse est eadem placere ei cui nisi optima placere non possunt, nec ob hoc minus liber est ac potens; ipse est enim necessitas sua.

4. nisi ad haec admitterer, non fuerat operae pretium nasci. quid enim erat cur in numero uiuentium me positum esse gauderem? an ut cibos et potiones percolarem? ut hoc corpus causarium ac fluidum, periturumque nisi subinde suppletur, farcirem, et uiuerem aegri minister? ut mortem timerem, cui uni nascimur? detrahe hoc inaestimabile bonum: non est uita tanti ut sudem, ut aestuem.

5. O quam contempta res est homo nisi supra humana surrexerit! quamdiu cum adfectibus conluctamur, quid magnifici facimus, etiamsi superiores sumus? portenta uincimus: quid est cur suspiciamus nosmet ipsos quia dissimiles deterrimis sumus? non uideo quare sibi placeat qui robustior est in ualetudinario:

6. multum interest inter uires et bonam ualetudinem. effugisti uitia animi? non est tibi frons ficta, nec in alienam uoluntatem sermo compositus, nec cor inuolutum, nec auaritia quae quidquid omnibus abstulit sibi ipsi neget, nec luxuria pecuniam turpiter perdens quam turpius reparet, nec ambitio quae te ad dignitatem nisi per indigna non ducet? nihil adhuc consecutus es: multa effugisti, te nondum. Virtus enim ista quam adfectamus magnifica est non quia per se beatum est malo caruisse, sed quia animum laxat et praeparat ad cognitionem caelestium, dignumque efficit qui in consortium $<$ cum $>$ deo ueniat.

7. tunc consummatum habet plenumque bonum sortis humanae cum calcato omni malo petit altum et in interiorem naturae sinum uenit. tunc iuuat inter ipsa sidera

${ }^{10}$ Utilizamos aqui o texto conforme estabelecido por Hine (1996). 
A contemplação da natureza e o sumo bem segundo Sêneca: tradução comentada do prefácio do livro I das Naturales Quaestiones

uagantem diuitum pauimenta ridere et totam cum auro suo terram, non illo tantum dico quod egessit et signandum monetae dedit. sed illo quod in occulto seruat posterorum auaritiae.

8. non potest ante contemnere porticus et lacunaria ebore fulgentia et tonsiles siluas et deriuata in domos flumina quam totum circuit mundum, et terrarum orbem superne despiciens angustum ac magna ex parte opertum mari, etiam ea qua extat late squalidum et aut ustum aut ringentem, sibi ipse dixit: 'hoc est illud punctum quod inter tot gentes ferro et igne diuiditur!'

9. O quam ridiculi sunt mortalium termini! ultra Histrum Dacus non exeat, imperium Haemo Thraces includant, Parthis obstet Euphrates, Danuuius Sarmatica ac Romana disterminet, Rhenus Germaniae modum faciat, Pyrenaeus medium inter Gallias et Hispanias iugum extollat, inter Aegyptum et Aethiopas harenarum inculta uastitas iaceat.

10. si quis formicis det intellectum hominis, nonne et illae unam aream in multas prouincias diuident? cum te in illa uere magna sustuleris, quotiens uidebis exercitus subrectis ire uexillis et, quasi magnum aliquid agatur, equitem modo extrema cingentem, modo ulteriora explorantem, modo a lateribus adfusum, libebit dicere 'it nigrum campis agmen.' formicarum iste discursus est in angusto laborantium. quid illis et uobis interest nisi exigui mensura corpusculi?

11. punctum est istud in quo nauigatis, in quo bellatis, in quo regna disponitis, minima etiam cum illis utrimque oceanus occurrit. Sursum ingentia spatia sunt, in quorum possessionem animus admittitur, <s>ed ita, si secum minimum ex corpore tulit, si sordidum omne detersit et expeditus leuisque ac se contentus emicuit.

12. cum illa tetigit, alitur, crescit, uelut uinculis liberatus in originem redit, et hoc habet argumentum diuinitatis suae quod illum diuina delectant, nec ut alienis sed ut suis interest. nam secure spectat occasus siderum atque ortus et tam diuersas concordantium uias; obseruat ubi quaeque stella primum terris lumen ostendat, ubi columen eius [summum cursus] sit, quousque descendat. curiosus spectator excutit singula et quaerit. quidni quaerat? scit illa ad se pertinere.

13. Tunc contemnit domicilii prioris angustias. quantum est enim quod ab ultimis litoribus Hispaniae usque an Indos iacet? paucissimorum dierum spatium, si nauem suus ferat uentus. at illa regio caelestis per triginta annos uelocissimo sideri uiam praestat nusquam resistenti sed aequaliter cito. illic demum discit quod diu quaesit, illic incipit deum nosse. quid est deus? mens uniuersi. quid est deus? quod uides totum et quod non uides totum. sic demum magnitudo illi sua redditur, qua nihil maius cogitari potest, si solus est omnia, si opus suum et intra et extra tenet.

14. Quid ergo interest inter naturam dei et nostram? nostri melior pars animus est, in illo nulla pars extra animum est. totus est ratio, cum interim tantus error mortalia tenet ut hoc quo neque formosius est quicquam nec dispositius nec in proposito constantius existiment homines fortuitum et casu uolubile, ideoque tumultuosum, inter fulmina nubes tempestates et cetera quibus terrae ac terris uicina pulsantur. 
15. nec haec intra uulgum dementia est, sed sapientiam quoque professos contingit. sunt qui putent ipsis animum esse et quidem prouidum, dispensantem singula et sua et aliena, hoc autem uniuersum, in quo nos quoque sumus, expers consilii auferri temeritate quadam, aut natura nesciente quid faciat.

16. quanti aestimas ista cognoscere et rebus terminos ponere, quantum deus possit, materiam ipse sibi formet an data utatur, utrum utro prius sit, materiae superuenerit ratio an materia rationi, deus quidquid uult efficiat an <in> multis rebus illum tractanda destituant, <ut> et a magno artifice praue multa formantur, non quia cessat ars, sed quia id in quo exercetur saepe inobsequens arti est?

17. haec inspicere, haec discere, his incubare, nonne transilire est mortalitatem suam et in meliorem transcribi sortem? 'quid tibi' inquis 'ista proderunt?' si nihil aliud, hoc certe: sciam omnia angusta esse mensus deum.

\section{Tradução}

1. Lucílio, melhor dos homens ${ }^{11}$, quanto há entre a filosofia e as outras $\operatorname{artes}^{12}$, é quanto estimo haver, no interior da própria filosofia, entre aquela parte

\footnotetext{
${ }^{11}$ Esse vocativo com que Sêneca se refere a Lucílio aqui parece importante, uma vez que o genitivo plural delimita o alcance do superlativo elogioso: primeiro, Sêneca limita o âmbito da comparação (os homens), por último, alça Lucílio à posição mais elevada dentro desse âmbito restrito. A ordem das palavras também destaca uir, que será logo a seguir contrastado com deus. Sêneca salienta que mesmo o que há de melhor entre os homens ainda não se compara à parte da natureza de que ele vai tratar, aos deuses. Não mantivemos a ordem usada por Sêneca para não dificultar a leitura, porém, também evitamos traduções mais livres, como "excelent man" (HINE, 2010, p. 136) ou "ottimo Lucilio" (PARRONI, 2008, p. 9), que perdem a ideia de comparação dentro de um campo delimitado. Essa estrutura de elogio restrito é a própria base da construção argumentativa de todo o prefácio: ser o melhor entre os homens é como ser o menos doente entre os enfermos de um hospital ( $v$. parágrafo 5 , abaixo).

12 Hine (2010, p. 136) traduz "between philosophy and other areas", Díaz (2013, 1. 9191), "entre la filosofía y las ciencias" e Parroni (2008, p. 9), "fra la filosofia e le altre discipline" (destaques nossos). 0 termo ars, correlato latino para o grego TÉx $\eta_{\eta}$, salienta o aspecto da ação, o pôr em prática um conhecimento que não seja meramente teórico, mas também a competência preexistente que possibilita a ação adequada. Por essa razão, evitamos acomodar o discurso de Sêneca à divisão contemporânea das disciplinas, em que a filosofia é tomada como disciplina eminentemente teórica. Sêneca debruça-se mais detidamente sobre os tipos de artes nas Ep. 87 e 88. Ali, o filósofo expõe uma hierarquia das artes em que aquelas relacionadas a trabalhos manuais, como a arte do cozinheiro, do condutor de navios e mesmo do médico (Ep. 87, 17), assim como as artes do pintor, do escultor, do marmorista e do lutador (Ep. 88, 18), ocupam o posto mais baixo, ao passo que as artes liberais ocupam o posto mais elevado abaixo da filosofia. Vale acrescentar um breve comentário sobre a tradução de interest. Seria possível traduzi-lo de forma mais simples por "difere", entretanto, optamos por manter a metáfora espacial característica de Sêneca ao longo desse prefácio não só na repetição de interest em quid illis et nobis interest (par. 10) e quid ergo interest inter naturam dei et nostram? (par. 14), mas também em multum interest inter uires et bonam ualetudinem (par. 6). Ademais, "difere" é um termo mais neutro, isento de um juízo de valor, ao passo em que interest coloca um dos termos comparados como algo mais avançado ou mais elevado do que o outro.
} 
A contemplação da natureza e o sumo bem segundo Sêneca: tradução comentada do prefácio do livro I das Naturales Quaestiones

pertinente aos homens ${ }^{13}$ e esta, pertinente aos deuses ${ }^{14}$. Esta última é mais elevada e mais ousada ${ }^{15}$; permitiu-se ${ }^{16}$ algo grande ${ }^{17}$. Não se contentou com os olhos: suspeitou haver algo maior e mais belo que a natureza possuísse além do que é visível.

2. Em suma, há tanto entre as duas quanto entre deus e homem ${ }^{18}$ : uma ensina o que se deva fazer nas terras ${ }^{19}$; a outra, o que ocorra no céu; uma dissipa nossos erros e aporta luz com a qual sejam discernidas as coisas ambíguas da vida; a outra [nos] retira [para] muito acima desse nevoeiro espesso no qual somos revolvidos ${ }^{20} \mathrm{e}$, das trevas arrebatados, [nos] conduz até a [própria] fonte da luz ${ }^{21}$.

3. Por isso, então, agradeço à natureza das coisas quando a vejo não desde aquela parte que é pública ${ }^{22}$, mas quando penetrei seus aspectos mais secretos, quando aprendo qual é a matéria do universo, quem o [seu] autor ou guardião,

${ }^{13}$ Isto é, a ética, ou seja, grande parte da obra em prosa de Sêneca. A Ep. 89 é toda dedicada à explicação da divisão da filosofia estoica em três partes "a ética, a física e a lógica. A primeira forma o caráter, a segunda estuda a natureza, a terceira estuda o valor dos vocábulos, a estrutura do discurso e as formas de argumentação" (Ep. 89, 9). Todas as citações das Epistulae Morales são feitas aqui a partir da tradução de José A. Segurado e Campos (2004).

${ }^{14}$ Isto é, a física. Conforme resume Algra (2013, p. 189), "pode-se afirmar que a teologia era a parte mais importante da física estoica e mesmo de toda a filosofia estoica. Mesmo os tratados estoicos exclusivamente consagrados à vida boa deviam ser baseados no esboço de uma visão geral do mundo, e essa forma 'atenuada' de física era globalmente limitada às questões teológicas: a exposição da ordem providencial e da afinidade entre o espírito do homem virtuoso e deus".

${ }^{15}$ Animosior: mais corajosa, mais aventurosa.

${ }^{16}$ Permisit (per + mittere): a muito se aventurou, não se restringiu, permitiu-se ir além dos olhos.

$17 \mathrm{O}$ adjetivo multum está no singular: "se permitiu uma coisa grande!". Não confundir com "muitas coisas" (multa).

${ }^{18}$ Entre um deus e um homem ou entre o deus e o homem. A inexistência de artigo em latim deixa ambígua a construção. Num mundo politeísta, os estoicos falam de um deus único que, porém, não deve ser confundido com o Deus da tradição judaico-cristã. Imitamos aqui Merckel (2012, p. 5), que evita essa ambiguidade traduzindo as referências de Sêneca ao deus estoico, quando inequívocas, para o francês "le dieu", contrastando assim tanto com "un dieu", que se refere a um deus do panteão clássico, quanto com "Dieu" (com inicial maiúscula e sem artigo) que, na tradição Ocidental, normalmente se refere ao Deus da tradição judaico-cristã.

${ }^{19} 0$ plural de Sêneca pode se referir de modo genérico ao conjunto das pátrias, de modo que poderia simplesmente ser traduzido como "terra", designando o planeta conhecido como um todo, em oposição ao caelum. Com efeito, essa foi a opção tradutória de Parroni (2008, p. 9, terra), Hine (2010, p. 136, Earth) e Díaz (2013, l. 9195, tierra). Porém, para dar esse mesmo sentido singular/coletivo, Sêneca poderia usar orbis terrarum (como de fato, fará um pouco adiante, no parágrafo 8), de modo que a opção por "terras" parece salientar uma pluralidade de costumes (vómos) em contraste com a unidade na natureza (фú́oı). Cf. Ep. 90, 3, em que Sêneca aponta como uma das consequências dos estudo da filosofia e da natureza a percepção de que, a despeito da aparente diversidade entre povos e classes, "a condição humana é a mesma para todos".

${ }^{20} \mathrm{~A}$ ordem das palavras somada à deliberada omissão da preposição ( $\mathrm{ad}$ ou, mais provavelmente, in) gera uma ambiguidade sintática, porém, os dois sentidos convergem: inicialmente pensamos que multum supra... caliginem é aposto para altera e diz o lugar onde ela está. Mas quando chega o verbo no fim da frase percebemos que se trata do lugar para onde ela leva. Porém, parece que ambas as interpretações são válidas e ela nos leva "para junto de si" (ad) e "para dentro de si" (in).

${ }^{21}$ Literalmente, "até ali donde reluz", "até [o lugar] donde vem a luz".

${ }^{22}$ O latim publica poderia ser aqui traduzido por "comum" ou "banal". Optamos, contudo, por seu cognato português por entender que seria relevante manter a oposição entre publica e secretiora presente no original. 
o que é o deus, se [ele] se debruça inteiramente sobre si mesmo ou se de vez em quando também a nós lança um olhar, se faz cada dia alguma coisa ou se fez [de] uma só vez, se é parte do mundo ou o [próprio] mundo, se lhe é lícito ainda hoje decretar [algo novo] e derrogar alguma coisa da lei dos fados, ou se seria uma diminuição de [sua] majestade e uma confissão de erro ter feito coisa que haveria de ser mudada. < Porém>, é necessário que a mesma coisa agrade [sempre] àquele a quem nada senão o melhor pode agradar, nem por isso é menos livre ou, sequer ${ }^{23}$, menos poderoso, pois ele próprio é a sua necessidade 24 .

4. Se eu não tivesse acesso a estas coisas, não teria valido a pena nascer, pois que motivo haveria para que me alegrasse de ter sido posto no número dos vivos? Acaso para que filtrasse comidas e bebidas? ${ }^{25}$ Para encher este corpo inconsistente e efêmero e [sempre] na iminência de perecer se não for repetidamente suplementado, para viver, enfim, como serviçal de um doente? Para temer a morte como única coisa para qual nascemos? ${ }^{26}$ Subtrai esse inestimável bem, e a vida já não valerá o suficiente para que eu sue e me alvoroce.

5. Ah! Quão desprezível coisa é o homem se não se ergue acima das coisas humanas! Enquanto lutamos com nossas paixões ${ }^{27}$, o que fazemos de magnífico,

\footnotetext{
${ }^{23}$ As conjunções aditivas ac/atque e et são sinônimas, porém, há uma importante diferença no fato de que ac/atque é mais enfático. Uma boa forma de ilustrar a importância dessa diferença é tomarmos o célebre Catulo V, 1: uiuamus, mea lesbia, atque amemus. Podemos traduzir esse atque simplesmente por "e", de modo que teríamos "viver" e "amar" meramente como duas ações concomitantes no mesmo nível. Contudo, assim perderíamos todo o efeito poético do verso, que consiste no fato de que Catulo acrescenta "amar" como um nível a mais, que vai além do mero "viver" e é um aprofundamento deste, de modo que temos uma gradação: "vivamos, minha Lésbia... mais do que isso, amemos!". Do mesmo modo, aqui, ao usar $a c$ e não meramente et (nec ob hoc minus liber est ac potens), Sêneca previne que o leitor pense: "Menos livre não, mas apenas menos poderoso". Ela dá mais um nível de profundidade à negação e afirma que não, nem sequer menos poderoso ele se torna por causa disso. ${ }^{24}$ Necessitas. A sua lei. A sua lógica.

${ }^{25}$ Cf. em Hesíodo (Teogonia, 26) o vocativo usado pelas musas para dirigir-se ao poeta mortal: "Pastores rústicos, infâmias vis, ventres somente" (tradução de Christian Werner, 2013).

${ }^{26}$ Uni: adjetivo modificando "morte". 0 topos da morte única para todos e niveladora da condição dos mortais é frequente em Sêneca e na literatura latina em geral; cf. Ep. 91, 16; Ad Marciam, 20,12; De ira, III, 43, 1; Troades, 434; NQ, II, 59, 4. Tosi (1996, p. 291) menciona também Claudiano (De raptu Proserpinae, II, 302), Plauto (Trinummus, 491-494) e Horácio (Odes, I, 4, 13ss., II, 3, 21-24; II, 18, 32 36). Acrescente-se ainda Catulo, V, 6. A tradução "temer a morte como" entende que a sequência introduz um predicativo do objeto. Outra possibilidade seria que se trata de um aposto predicativo, e teríamos algo como: "para temer a morte, a única coisa para a qual nascemos?". As duas interpretações são bastante diferentes, uma vez que a primeira pressupõe erro em crer que a morte seja a única coisa para a qual nascemos, ao passo que a segunda pressupõe apenas que é erro temêla, admitindo-se que ela seja a única coisa para a qual nascemos. Independentemente de Sêneca, como estoico, ter uma concepção definida sobre a morte, seu discurso sobre ela deixa frequentemente a questão em aberto. Cf. por exemplo as palavras de encerramento da $E p .65$ : "O que é a morte? Ou é termo ou é passagem. Não receio chegar ao termo, pois ficarei no mesmo estado de quem nunca nasceu; também não receio a passagem, pois em lugar algum estarei tão limitado quanto aqui!". A essa passagem, Segurado Campos (2004) apõe a seguinte nota: "Não deverá ver-se aqui uma indecisão de Séneca ou um mal entendido ecletismo, mas apenas a obediência a um princípio da pedagogia estoica que, desde Crisipo, aconselhava a não contrariar frontalmente as convicções prévias dos discípulos, mas antes a, partindo desta e reinterpretando-as, levá-las gradualmente às posições da Escola".

${ }^{27}$ Quamdiu cum adfectibus conluctamur.
} 
ainda que nos mostremos superiores? Vencemos monstros: que motivo há para que nos admiremos a nós mesmos 28 [apenas] por sermos diferentes dos piores? Não vejo nenhuma razão para que se compraza de si mesmo aquele que é o mais robusto num hospital ${ }^{29}$.

6. Há um abismo entre vigor e boa saúde. Escapaste dos vícios da alma? Não tens rosto fingido, nem tua conversa é regulada de acordo com a vontade alheia? Nem carregas um coração dissimulado ou avareza que negue a si mesma o que quer que tolha a todos? Nem intemperança ${ }^{30}$ que perde dinheiro torpemente e o recupera de modo ainda mais torpe? Nem tens ambição que te conduza às honrarias apenas através de coisas desonrosas? Até aqui, ainda não conseguiste nada. Escapaste de muitas coisas, mas de ti mesmo, ainda não. Pois esta tal virtude a que aspiramos ${ }^{31}$ é engrandecida não porque é ${ }^{32}$ um bem em si chegar a carecer ${ }^{33}$ de males, mas porque expande [laxat] e prepara o espírito para o conhecimento das coisas celestes, e o torna digno de que chegue à comunhão $<$ com> o deus.

7. [Só] então, quando, calcado todo mal, busca as alturas e chega ao seio íntimo da natureza, tem plenamente realizado o sumo bem do destino humano. Então, vagando entre os próprios astros, agrada-lhe rir dos pavimentos dos ricos e de toda a terra com seu ouro, e não me refiro apenas ao ouro que [a terra] trouxe para fora e entregou para a cunhagem de moedas ${ }^{34}$, mas [também] àquele que, oculto, ela guarda para a avareza dos pósteros.

8. [O espírito] é incapaz de desprezar os pórticos e tetos reluzentes de marfim, os bosques podados e os rios desviados para dentro das propriedades privadas antes que tenha circundado o cosmo e, olhando do alto a Terra, (diminuta e, ademais, em sua maior parte coberta pelo mar e, mesmo na parte que aparece [acima do mar], largamente esquálida, ou abrasada pelo calor ou enrijecida pelo frio), tenha dito a si mesmo: 'é isto aquele ponto que entre tantos povos a ferro e fogo é dividido!'35

\footnotetext{
${ }^{28} 0$ pronome está duplamente enfatizado com a partícula -met e com o pronome adjetivo ipsos.

${ }^{29} \mathrm{O}$ trecho faz eco ao vocativo com que Sêneca se dirige a Lucílio: uirorum optime (dentre os os homens, o melhor, $N Q$ I, praef. 1).

${ }^{30}$ O latim luxuria poderia ser traduzido por seu cognato português "luxúria". Entretanto, tendo em vista que o termo português sofreu especialização semântica, passando a referir-se quase sempre a excessos especificamente no âmbito sexual, optamos por traduzi-lo por "intemperança", termo mais genérico que abarca excessos (luxos) em diversas áreas da vida.

${ }^{31}$ Cognato de adfectibus, usado no parágrafo anterior.

32 Pelo uso do modo indicativo, Sêneca indica concordar que seja um bem em si carecer de males. 0 que ele nega é que seja essa a razão por que ela seja tão engrandecida.

330 infinitivo perfectum salienta a ação de livrar-se dos males, a passagem de um estado (com males) para outro (sem males). Traduzi-lo meramente por nosso infinitivo (presente) seria perder esse sema da ação, da busca ativa (adfectamus) e dar a entender um estado natural de falta de males.

${ }^{34}$ Literalmente, "deu à cunhagem [local onde se cunha] para ser estampado" (signandum monetae dedit).

${ }^{35} \mathrm{~A}$ longa estrutura parentética está presente no original.
} 
9. Ah, quão ridículas são as fronteiras dos mortais! Que um dácio não saia para além do Istro, que os trácios encerrem com o Hemo o seu império, que aos partos o Eufrates seja barreira, que o Danúbio seja o limite entre o [território] sarmático e o romano, que o Reno dê termo à Germânia, que os Pireneus ergam seus cumes no meio entre Gálias e Hispânias, que entre Egito e Etiópia estendase uma vastidão inculta de areias...

10. Se alguém der às formigas o intelecto do ser humano, também elas não dividirão um metro quadrado em muitas províncias? ${ }^{36}$ Quando tu tiveres te elevado àquelas coisas verdadeiramente grandes, quantas vezes vires um exército marchar com bandeiras erguidas e um soldado da cavalaria ora rodeando a retaguarda, ora explorando [o caminho] à frente, ora espalhar-se pelos flancos, como se se tratasse de algo grandioso, te agradará dizer 'vai pelos campos o negro esquadrão' ${ }^{37}$. Esta é a deambulação de laboriosas formigas em limites estreitos. Que há entre elas e vós além da medida do exíguo corpinho?

11. Um ponto! é um ponto isto em que navegais ${ }^{38}$, em que guerreais, em que dispondes reinos, minúsculos mesmo quando de um e outro lado o oceano lhes encontra. Acima, há espaços ingentes na possessão dos quais o espírito é admitido, mas apenas na condição de que carregue consigo o mínimo do corpo, apenas se limpou toda sujeira e surgiu brilhante, desimpedido e leve e, além disso, contente consigo.

12. Quando alcançou aquelas coisas, alimenta-se, cresce, como que liberto das correntes, retorna à origem, e tem esse argumento para a sua divindade: que as coisas divinas o deleitam, e as observa não como alheias, mas como suas. Pois, estando livre de inquietações, assiste o ocaso e o nascimento dos astros e suas tão diversas vias de harmonização ${ }^{39}$; observa onde cada estrela por primeiro revela sua luz às terras, onde é o cume dela, até onde desce. Espectador curioso, perscruta e investiga cada detalhe. Como não investigaria, [posto que] sabe que aquelas coisas lhe concernem?

13. É então que despreza as estreitezas de sua morada anterior. Pois quanto é que jaz desde os mais avançados litorais da Hispânia até, por exemplo, a Índia? O espaço de pouquíssimos dias, se um vento favorável conduzir o

\footnotetext{
${ }^{36} \mathrm{O}$ topos do perspectivismo a partir da comparação entre homens e formigas aparece também na fábula 117 de Bábrio, cujo argumento implica que os homens estão para os deuses assim como as formigas estão para os homens.

${ }^{37}$ Eneida IV, 404. Agmen é o termo latino que designa especificamente o exército marchando em fila por uma estrada. No contexto desse hemistíquio citado, Virgílio compara os soldados troianos em marcha justamente a formigas e é por isso que Sêneca o cita aqui: "Pelos portões da cidade os vereis apressados correrem / como formigas no ponto em que um monte de trigo saqueiam, / quando do inverno mais perto e a seus paços escuros o levam: vai pelos campos o negro esquadrão carregando pilhagem" (Eneida IV, 401-404, tradução de Carlos Alberto Nunes, 2014).

38 Punctum. Sêneca brinca com uma palavra latina que significa "mar": pontus.

${ }^{39}$ Literalmente, "as tão diversas rotas dos [astros] que se harmonizam".
} 
navio ${ }^{40}$. Por sua vez, aquela região celeste oferece uma jornada de trinta anos a um velocíssimo astro que nunca se detém, mas é uniformemente rápido. Ali finalmente aprende o que buscou por muito tempo. Ali começa a conhecer o deus. O que é o deus? A mente do universo. O que é o deus? Tudo o que vês e tudo o que não vês ${ }^{41}$. Assim, finalmente, sua grandeza lhe é devolvida, e nada pode ser imaginado maior do que ele, se sozinho é todas as coisas, se sustenta sua obra a partir de dentro e de fora.

14. O que há, portanto, entre a natureza do deus e a nossa? De nós, a melhor parte é o espírito: nele não há nenhuma parte além do espírito. Ele é todo razão, ao passo que, entrementes, um erro tão grande aprisiona as coisas dos mortais que as pessoas estimam que este [universo] (mais belo, mais ordenado e mais constante no propósito do que qualquer coisa particular) seja fortuito e volúvel ao acaso, e, por isso, tumultuoso, em meio a raios, nuvens, tempestades e outras coisas pelas quais as terras e as partes vizinhas a elas ${ }^{42}$ são fustigadas.

15. Tampouco essa demência se limita ao vulgo, mas toca também os que professam sabedoria. Há aqueles que julgam que eles mesmos têm um espírito, ainda mais, previdente e capaz de administrar tanto as suas coisas como as alheias, que esse universo, porém, no qual também nós estamos, desprovido de plano seria arrastado por certa temeridade ou por uma natureza que não sabe $o$ que faz.

16. Quanto vale para ti conhecer isto e determinar os limites das coisas: quanto pode o deus? se ele próprio cria a matéria ou faz uso de [matéria] dada? Qual dessas duas coisas é anterior à outra: a razão precede a matéria, ou a matéria [precede] a razão? O deus leva a cabo tudo quanto queira ou <em $>$ muitas coisas o desamparam as coisas que deve manejar, <assim como> muitas coisas são defeituosamente fabricadas mesmo por um grande artífice, não porque lhe falte $\operatorname{arte}^{43}$, mas porque aquilo em que ela é exercida muitas vezes é arredio à arte?

17. Examinar ${ }^{44}$ essas coisas, aprendê-las, meditar sobre elas, não é saltar por sobre sua mortalidade e ser transferido para uma sorte melhor? Dizes: "em que essas coisas te são proveitosas?" 45 . Se em nenhuma outra coisa, nisso com certeza: mensurado o deus, saberei que tudo o mais é estreito.

\footnotetext{
${ }^{40}$ Como assinala Díaz (2013, 1. 9863), este foi um dos trechos de autores clássicos que motivaram Cristóvão Colombo a buscar uma rota para as Índias pelo oeste.

${ }^{41}$ Optamos por traduzir totum em sentido numeral: "tudo que". Contudo o termo também carrega um importante sentido de inteireza, "o todo", de modo que poderíamos igualmente traduzir o trecho como "o todo que vês e o todo que não vês", ou "o que vês como todo e o que não vês como todo".

${ }^{42}$ Sêneca refere-se à atmosfera terrestre, onde ocorrem fenômenos meteorológicos.

${ }^{43} \mathrm{Ars}$. Veja-se a discussão sobre o termo na nota 9.

${ }^{44} \mathrm{O}$ termo latino inspicere (in + spicere $^{*}$ ) traz a ideia de olhar para dentro, o que ecoa as palavras intraui e secretiora, usadas anteriormente (NQ, I, praef. 3) por Sêneca.

${ }^{45}$ Sêneca põe essa mesma pergunta retórica na boca de Lucílio em Ep. 65, 15, em que discute justamente a validade do estudo da física.
} 


\section{REFERÊNCIAS}

ALGRA, Keimpe. Cosmologia e teologia. In: GOURINAT, J. B.; BARNES, J. (org.).

Ler os estoicos. Tradução de Paulo S. R. C. Silva. São Paulo: Edições Loyola, 2013 [2009], p. 175-195.

CAMPOS, J. A. S. e. (trad.). Sêneca. Cartas a Lucílio. Lisboa: Fundação Calouste Gulbankian, 2004.

CARDOSO, Z. de A. A literatura latina. $3^{a}$ ed. São Paulo: Martins Fontes, 2013.

CITRONI, M. et alii. Literatura de Roma Antiga. Tradução de Margarida Miranda e Isaías Hipólito. Lisboa: Calouste Gulbenkian, 2006.

DÍAZ, José Román Bravo (trad.). Seneca. Cuestiones Naturales. Introducción, traducción y notas de José-Román Bravo Díaz. Edição do Kindle. Madrid: Editorial Gredos, 2013.

HINE, Harry (ed.). Lucius Annaeus Seneca. Opera. Naturalium Quaestionum

411 Librei. Bibliotheca Scriptorum Graecorum et Romanorum Teubneriana. Stuttgart und Leipzig: De Gruyter, 1996.

HINE, Harry (trad.). Seneca. Natural Questions. Translated by Harry Hine. Chicago: The University of Chicago Press, 2010.

MERCKEL, Cécile. Seneca theologus: la religion d'un philosophe romain. 2012. 553 f. Tese (Doutorado em Philologie classique) - Sciences de l' Antiquité, Université de Strasbourg, Strasbourg (França), 2012.

NUNES, Carlos Alberto. Virgílio. Eneida. Tradução. São Paulo: Ed. 34, 2014.

PARRONI, Piergiorgio (trad.). Seneca. Ricerche sulla natura. A cura di Piergiorgio Parroni. Milão: Mondadori, 2008.

RAIJ, C. F. de M. van. (trad.). Sêneca. Cartas consolatórias. Campinas: Pontes, 1992.

TOSI, Renzo. Dicionário de Sentenças Latinas e Gregas. Tradução de Ivone Castilho Benedetti. São Paulo: Martins Fontes, 1996. 
A contemplação da natureza e o sumo bem segundo Sêneca: tradução comentada do prefácio do livro I das Naturales Quaestiones

WERNER, Christian. Hesíodo. Teogonia. Organização e tradução do grego. São Paulo: Hedra, 2013.

Data de envio: $27 / 08 / 2020$

Data de aprovação: 05/10/2020

Data de publicação: 21/12/2020 